RESEARCH REPORT

\title{
VISUAL SUPPORT REDUCES ANXIETY IN AUTISM SPECTRUM DISORDER AND ENHANCE THEIR VISUAL PERCEPTUAL SKILLS
}

\begin{abstract}
BACKGROUND

Children with Autism Spectrum Disorder (ASD) have difficulties with sensory processing that result in anxiety in certain situations. Aim of this study is to determine the efficacy of visual supports in reduction of anxiety levels and tolerance of transitions or switch over in children with ASD.
\end{abstract}

\section{STUDY DESIGN}

Randomized controlled trial

\section{METHODS}

With a sample size of 57, comparison was made between two groups i.e.; the experimental and the control group to see the efficacy of the visual inputs in reducing anxiety in children with ASD of age bracket 8-12 years old. Experimental group was given visual aids with occupational therapy sessions, while control group was only given conventional Occupational Therapy sessions. Pre and post analysis of visual perceptual ages and the anxiety levels of children were compared by anxiety scale for children-spectrum disorder and motor-free visual perception test.

\section{RESULT}

Significant increase in the visual perceptual ages with reduction in anxiety level was observed in experimental; no significant difference was found in control group.

\section{CONCLUSION}

Reduction in the anxiety levels was achieved after 4 weeks of intervention with improvement in the visual perceptual ages in the experimental group.

\section{KEYWORDS}

Visual Aids, Autism, Sensory Functioning, Anxiety, Intervention, Perceptual.

\author{
Ramsha Ghous \\ Occupational Therapist \\ Centre for Child Development \\ rg_taurus@hotmail.com \\ Hina Naz \\ Occupational Therapist \\ Institute of Physical Medicine and Rehabili- \\ tation \\ DUHS \\ hinanazot2012@gmail.com
}

[Ghous R, Naz H. Visual support reduces anxiety in autism Spectrum disorder and enhance their visual perceptual skills. Pak. j. rehabil. 2019;8(1):31-36] 


\section{INTRODUCTION}

The most rising disorder in last five years includes Autism Spectrum Disorder (ASD) as shown by the increased incidence rate globally. In March 2013, it was estimated by the Center for Disease Control, that one in every 50 school going children was diagnosed with autism spectrum disorder. In compare to the data of 2012, $1.16 \%$ increase in ASD was found in 2013'. Worldwide the prevalence of ASD is reported as $1.4 \% ; 185$ children out of 10,000 children². A study conducted in 2012 shows that in the last five years $56 \%$ children in UK were diagnosed with autism ${ }^{3}$. An average prevalence ranging between $1 \%$ and $2 \%$ marks in Asia, Europe and North America $^{4}$. While considering a survey conducted in Pakistan there is lack of awareness of autism spectrum disorder, teachers and parents are not well aware about the special education needs of these children ${ }^{5}$. South Asian Countries also have high prevalence being $0.09 \%$ in India and $1.07 \%$ of population in Sri Lanka that makes 1 in 93 children in this region'. Autism affects more than 3.5 million Americans annually ${ }^{7}$.

Children with autism spectrum disorder are good in receiving visual information such as still pictures; flash cards, models etc. but abstract concepts and language are difficult to understand for most children. Visual learningis better than auditory learning; alternative modes of communications such as pictures rather than written words are preferred for such children. In spite of crucial gains in the interventional strategies that benefit individuals with autism spectrum disorder, the treatment approach has been complex, they pause lot of challenges including difficulties with sensory processing, daily living tasks, colorstoleration, poor cognition and low visual perceptions ${ }^{8}$. Recent researches showed that providing visual supports such as tele-health system and virtual reality helped the student with autism in their social learning and boost up positive behaviours?. Evidences show that children with autism better understand visual inputs rather than hearing ${ }^{10}$. Finding of one study revealed the importance of visual activity in promoting the independent functioning and problem solving skills of students with autism spectrum disorder in their confined environments ${ }^{11}$. Current studies about relevancy of anxiety with autism showed that 17 percent of children showed traditional anxiety, and 31 percent showed combination results ${ }^{12}$.

Variety of tools are available for measuring anxiety levels which includes Multidimensional Anxiety Scale for Children (MASC-C), Pediatric Anxiety Rating Scale, Anxiety Diagnostic Interview Scale for DSM IV, The Spence Children's Anxiety Scale and Anxiety Scale for Children (ASCASD). Out of all these scales ASCASD is report to have good reliability and validity ${ }^{3}$. Findings suggest that home and school Treatment and Education of Autistic and related Communication Handicapped Children (TEACCH) program may reduce symptoms of stress and anxiety in children with autism spectrum disorder ${ }^{14}$.

One of the most common problems faced by children with autism spectrum disorder is anxiety. Anxiety related symptoms seemed to be more common among the high functioning autism and Asperger's syndrome. Asperger's syndrome is a type of pervasive developmental disorder, in which the child lags development of basic skills such as social interaction, language skills and analytical skill ${ }^{15}$.

Occurrence of anxiety in Autism Spectrum Disorder appears to be closely associated with sensory processing dysfunctions. Mindful based programs for autistic children and their parents are considered as significant assessment tools for measuring anxiety levels in autism spectrum disorder. These programs should be managed well for better outcomeand enhancing capabilities to understand their world in a better way which has positive impact on communication, behavioral and functional issues ${ }^{16}$. It is statistically proved in a study that early intervention programs including occupational therapy, speech and language therapy can help prevent or minimize behavioral and cognitive issues in $\mathrm{ASD}^{17}$.

\section{METHODOLOGY}

\section{Setting}

The study was carried out under an NGO at public sector hospital.

\section{Targeted Population}

Children between 8-12 years of age fulfilling the criteria of mild to moderate autism.

\section{Study Design}

Randomized Control Trial(RCT)

\section{Duration of Study}

The study was carried out in an estimated duration of 4 weeks.

\section{Sample Size}

57 known cases of Autism Spectrum Disorder.

\section{Sampling Technique}

A convenient sampling.

\section{Data Collection Procedure}

Subjects were randomized into experimental group and the control group. 27 subjects were in the control group and 30 in the experimental group. Information of the study subjects were recorded at the start and at the end of four weeks therapy. The occupational therapy sessions were conducted 4 times a week making it a total of 16 sessions for the participants of both the groups. Designed activities were same for both with exception of the visual aids for the experimental group; that includedthree activities out of which two were fine motor activities and one was gross motor. Activities planned for the 
therapy session includes tracing and lacing beads activity (fine motor)and jumping on a trampoline/ circular discs (gross motor). These activities were implemented for assessing the difference in the anxiety levels and the difference in the perceptual ages of the subjects.

\section{Data Collection Tool}

The relative data was gathered by noticing the improvement levels in the responses, gestures, and verbal judgments of the individuals. The result was then assessed by using anxiety scale for children (ASC-ASD). A total score of $\geq 20$ indicated the presence of significant levels of anxiety. Scores higher than 24 on ASC-ASDare considered as more specific result. It was a questionnaire based scale to find out the effects of visual supports in children and the change in their responses were noted accordingly. For the assessment of visual perception motor free visual perception test (MVPT-R) was used.It covered five areas including spatial relationships, visual discrimination, figure ground, visual closure and visual memory.

\section{Data Analysis}

Data was analyzed using SPSS version 20.Pre post analysis within the group was made by using paired T-test and between the group comparisons were done by using independent $\mathrm{T}$ test.

\section{Inclusion Criteria}

- Children between the ages of 8-12years2

- Male and female children diagnosed with Autism Spectrum Disorder2.

- Autism spectrum disorder level mild to moderatel 1.

\section{Exclusion Criteria}

- Comorbid physical disability ${ }^{2}$

- Visual impairment ${ }^{11}$

- Hearing impairment ${ }^{11}$

\section{Ethical Consideration}

The identity of all the subjects was kept confidential while maximizing the benefits and minimizing the risk factors and well considered procedures were administered fairly. Informed consent was obtained from the parents.

\section{RESULT}

A total of 57 participants were recruited in this study. Selection was done on the basis of convenience sampling technique.

As shown in figure 1 there were 27 male and 3 female

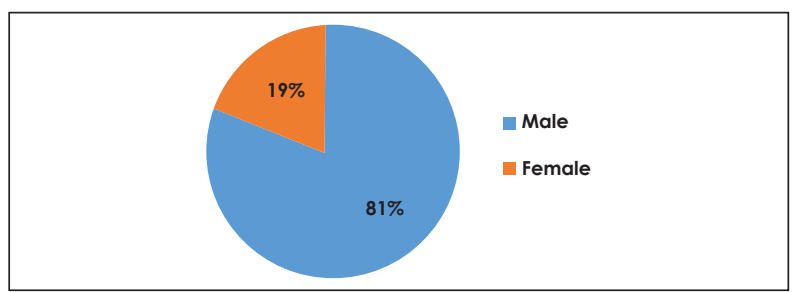

Figure 1. Population of the Study in Experimental group and 19 male and 8 female in control group.

The motor free visual perceptual test was applied to find out the perceptual age of child.

Tablel shows that the mean perceptual age of experimental Pretest group was 5.14 with standard deviation of \pm 0.92 then paired T test was applied to find out the difference in pre \& post -test of Experimental group mean score for pretest is 5.13 with a SD \pm 0.97 and for post were 5.76 with a SD of \pm 1.52 . A significant difference was observed with a $p$ value of 0.0026 that is highly significant.

Table 1. Mean perceptual age of experimental Pretest group

\begin{tabular}{|c|c|c|}
\hline & $n$ & Means \pm SD \\
\cline { 1 - 1 } Pre & \multirow{2}{*}{30} & 5.13 SD 0.97 \\
\cline { 1 - 1 } Post & 5.76 SD 1.52 \\
\hline
\end{tabular}

As shown in table 2T test was applied for control group pre- test and the mean difference noted was 4.80 with a SD of \pm 0.52 and for post- test mean was 4.91 with a SD of \pm 0.52 that shows no significance of data

\begin{tabular}{|c|c|c|}
\hline \multicolumn{3}{|c|}{$\begin{array}{l}\text { Table 2. Control group pre- test posttest mean } \\
\text { difference }\end{array}$} \\
\hline & $n$ & Means \pm SD \\
\hline Pre & \multirow{2}{*}{27} & 4.80 SD 0.57 \\
\hline Post & & 4.91 SD 0.52 \\
\hline
\end{tabular}

However when independent T test was applied to make post study comparison between both experimental and control group. Table 3 shows that the mean of experimental group was 5.76 with a SD of \pm 1.52 and mean of control group was 4.91 with a $\mathrm{SD} \pm 0.52$ which shows a highly significant $P$ value.

Table 3. Post study comparison of Experimental Controlled Group

\begin{tabular}{|c|c|c|c|}
\hline & $\mathrm{n}$ & Mean \pm SD & P-value \\
\hline $\begin{array}{c}\text { Post } \\
\text { (experimental) }\end{array}$ & 30 & $5.76 \pm 1.52$ & 0.0002 \\
\hline $\begin{array}{c}\text { Post } \\
\text { (control) }\end{array}$ & 28 & $4.91 \pm 0.52$ & \\
\hline
\end{tabular}

When paired T test was applied for the analysis of (ASC-ASD) experimental group pre- test mean was noted as 53.7 with a SD of \pm 0.66 and after 3 weeks its posttest mean was 35.6 with a SD of \pm 20.50 with a highly significant p value 0.000 as proven in table 4 . 


\begin{tabular}{|c|c|c|c|}
\hline \multicolumn{3}{|c|}{ Table 4. Pretest mean of experimental group } \\
\hline & $\mathrm{n}$ & Mean \pm SD & P-value \\
\hline pre & \multirow{3}{*}{30} & $53.7 \pm 0.66$ & \multirow{2}{*}{0.000} \\
post & & $35.6 \pm 20.50$ & \\
\hline
\end{tabular}

To analyze the pretest values of control group for (ASC-ASD) paired T test was applied which showed mean of 52.7 with a SD of \pm 6.78 and post- test mean was 51.82 with a SD of \pm 6.16 that shows non-significant $p$ value of 0.006 as shown in table 5.

\section{Table 5. Pretest mean of controlled group}

\begin{tabular}{|c|c|c|c|}
\hline & $n$ & Mean \pm SD & P-value \\
\hline $\begin{array}{c}\text { Post } \\
\text { (experimental) }\end{array}$ & 30 & $35.6 \pm 20.52$ & \multirow{2}{*}{0.0002} \\
\hline Post (control) & 28 & $51.82 \pm 6.16$ & \\
\hline
\end{tabular}

Table 6. Post study compression of experimental and controlled group

\begin{tabular}{|c|c|c|c|}
\hline & $n$ & Mean士 SD & P-value \\
\hline $\begin{array}{c}\text { Post } \\
\text { (experimental) }\end{array}$ & 30 & $52.7 \pm 6.78$ & \multirow{2}{*}{0.006} \\
\hline $\begin{array}{c}\text { Post } \\
\text { (control) }\end{array}$ & 28 & $51.82 \pm 6.16$ & \\
\hline
\end{tabular}

For Post study results comparison of (ASC-ASD) of both experimental and control group independent t- test was applied. Table 6 shows the post- test result of experimental group mean was 35.6 with a SD of \pm 20.52 and control group mean was 51.82 with a SD of \pm 6.16 showing highly significant $p$ value 0.0002 .

After the comparison of both groups a significant increase in perceptual age was identified with reduction in anxiety level in experimental group whereas in control group there was no significant change observed in perceptual ages as well as in anxiety level.

\section{DISCUSSION}

The effects of anxiety in children with autism spectrum disorder were assessed by using a questionnaire. Also the visual perceptual age of the children were assessed following the Motor-free visual perceptual standardized test. Two groups were followed over a period of 4 weeks and pre and post test comparison was carried out in all 57participants. Children and adults with autism are good visual learners having a requirement for structured environ- ment. Visual schedules serve as a bridge between them to respond effectively with good communication skills thus reducing anxiety moving them towards better performance. This research investigated the difference between the visual perceptual ages of children with autism spectrum disorder using MVPT-R scale. A significant rise of $63 \%$ was indicated in the visual perceptual ages of children. A parallel study was carried out to investigate the effects of picture exchange communication system Data collection was done in the picture exchange community system before training and after training. It was resulted that speech with picture is an effective way to increase the skills of autism spectrum disorder children ${ }^{15}$. A study was conducted to explore the level of anxiety in children with autism, the tool used to measure anxiety levels in such children was (ASC-ASD). Significantly high levels of anxiety were detected and (ASC-ASD) was found to be a reliable tool for measuring anxiety levels in autism spectrum disorder population ${ }^{17}$. The anxiety levels were reduced to almost $18.1 \%$ by occupational therapy interventions implemented on both groups in our research whereas a similar research was conducted in year 2013 that used Revised Children's Anxiety and Depression Scaleto measure anxiety levels in adolescents,subscales such as separation anxiety, panicdisorder,obsessive compulsive disorder, generalized anxiety disorder, social phobia and depression were also included. It was concluded that the measurements taken though the RCADS truly reflect changes in anxiety level ${ }^{18}$. Another study conducted to check reliability of the parent related anxiety scale that included parents of 990 children with autism spectrum disorder between 5 to 17 years, parents were advised to fill the 25 items based anxiety scale. This study proved that anxiety scale is reliable and valid to measure anxiety levels in autism spectrum disorder population ${ }^{19}$. It is also known that children with autism spectrum disorder also face difficulty in hand writing due to physical, sensory and cognitive impairment ${ }^{20}$. This can also be improved by the use of visual aids and occupational therapy Treatment sessions as given in our study. In another study group of 10 children were focused who had difficulty in understanding speech and communication. Those children were given visual support that resulted in better understanding and good academic progress ${ }^{21}$. When it comes to visual perception in dealing with children with autism spectrum disorder, similar marked improvement was seen in the functional status of children using visual supports. A standardized test for gross motor development 3 (TGMD-3) was used in a study. It was administered to 14 children with autism spectrum disorder aged between 4-10 years of age using the traditional visual support protocol with all the participants. Highly significant levels of consistency and accuracy were achieved $^{22}$. It is found that problem solving skills of children with autism spectrum disorder are also improved by giving them different tasks verbally. A researcher in 2014 worked on problem solving skills of children with autism spectrum disorder. Heused 
Twenty Questions Task to facilitate the problem solving skills in children withautism spectrum disorder. Fifteen participants with autism spectrum disorder and 15 with High Functioning Autism (HFA) were included in this study. Itled to improved problem solving skill but with efficacy difference in both groups $^{23}$. Another research came down to the same conclusion that the use of visual supports promotes better learning capacity while performing activities that we call as "on-task behavior" in classrooms with children with autism spectrum disorder ${ }^{24}$. The present study evaluated the effect of using visual aids visual perceptual ages and assessed anxiety in children with autism spectrum disorder. Although this study provides insight into relationship between child's perceptual age and level of anxiety, visual scheduling decreases the anxiety of an autistic child. A small sample size of 57 was selected with a limited duration of 4 weeks that does not provide a complete picture of these assessments although this research is best understood within a larger sample size.Due to limited time specification only one organization could be approached for data collection. This sample is relatively a small proportion of entire autism spectrum disorder population in the country. Therefore, research studies with larger sample size would ensure appropriate findings of the study25 26.This research has given an idea to promote the use of visual aids so it would help autism spectrum disorder population to deal with their visual deficits more independently and their quality of life will not be compromised further.

\section{CONCLUSION}

The results of the study concluded that the use of visual supports not only reduces anxiety levels in children with autism spectrum disorder but also improve their visual perceptual skills. Communicative alertness and better functionality with significant increase in the visual perceptual ages was seen in children who were given interventions with visual supports. Anxiety levels were reduced to a significant level in children of experimental group but not in the children of control group there was no increase in the visual perceptual ages of children those who were not given the visual aids as compared to the experimental group.

\section{REFERENCES}

[1] Zablotsky B, Black LI, Maenner MJ, Schieve LA, Blumberg SJ. Estimated prevalence of autism and other developmental disabilities following questionnaire changes in the 2014 National Health Interview Survey.

[2] Blumberg SJ, Bramlett MD, Kogan MD, Schieve LA, Jones JR, LU MC. Changes in Prevalence of Parent-Reported Autism Spectrum Disorder in School-Aged US Children: 2007 to 201 1-2012. National Center for Health Statistics Reports. Number 65. National Center for Health Statistics. 2013.

[3] Kim YS, Leventhal BL, Koh YJ, Fombonne E, Laska
E, Lim EC, Cheon KA, Kim SJ, Kim YK, Lee H, Song DH. Prevalence of autism spectrum disorders in a total population sample. American Journal of Psychiatry. 2011 Sep; 168(9):904-12.

[4] Baio, J., 2014. Prevalence of autism spectrum disorder among children aged 8 years-autism and developmental disabilities monitoring network, 11 sites, United States, 2010.

[5] Ayub A, Naeem B, Ahmed WN, Srichand S, Aziz K, Abro B, Najam S, Murtaza D, Janjua AA, Ali S, Jehan I. Knowledge and perception regarding autism among primary school teachers: A cross-sectional survey from Pakistan, South Asia. Indian J PrevSoc Med: official publication of Indian Association of Preventive \& Social Medicine. 2017;42(3):177.

[6] Hossain MD, Ahmed HU, Uddin MJ, Chowdhury WA, labal MS, Kabir RI, Chowdhury IA, Aftab A, Datta PG, Rabbani G, Hossain SW. Autism Spectrum disorders (ASD) in South Asia: a systematic review. BMC psychiatry. 2017;17(1):281.

[7] Skonieczna-Żydecka K, Gorzkowska I, Pierzak-Sominka J, Adler G. The prevalence of autism spectrum disorders in West Pomeranian and Pomeranian regions of Poland. J Appl Res Intellect Disabil. 2017;30(2):283-9.

[8] Weitlauf AS, Sathe N, McPheeters ML, Warren ZE. Interventions targeting sensory challenges in autism spectrum disorder: a systematic review. Pediatrics. 2017;139(6):e20170347.

[9] Aresti-Bartolome N, Garcia-Zapirain B. Technologies as support tools for persons with autistic spectrum disorder: a systematic review. J. Environ. Res2014;11(8):7767-802.

[10] Hayes GR, Hirano S, Marcu G, Monibi M, Nguyen $\mathrm{DH}$, Yeganyan $M$. Interactive visual supports for children with autism. Personal and ubiquitous computing. 2010;14(7):663-80.

[11] Diamond LL. Problem Solving Using Visual Support for Young Children with Autism. Intervention in School and Clinic. 2018;54(2):106-10.

[12] Van Steensel FJ, Bögels SM, Perrin S. Anxiety disorders in children and adolescents with autistic spectrum disorders: a meta-analysis. Clinical child and family psychology review. 2011 Sep 1;14(3):302. [13] Rodgers J, Wigham S, McConachie H, Freeston M, Honey E, Parr JR. Development of the anxiety scale for children with autism spectrum disorder (ASC-ASD). Autism Research. 2016:9(11):1205-15.

[14] D'Elia L, Valeri G, Sonnino F, Fontana I, Mammone A, Vicari S. A longitudinal study of the TEACCH program in different settings: The potential benefits of low intensity intervention in preschool children with autism spectrum disorderJ Autism DevDisord. 2014;44(3):615-26.

[15] Ridderinkhof A, de Bruin El, Blom R, Bögels SM. Mindfulness-based program for children with autism spectrum disorder and their parents: Direct and long-term improvements. Mindfulness. 2018:9(3):773-91.

[16] Zwaigenbaum L, Bauman ML, Choueiri R, Kasari C, Carter A, Granpeesheh D, Mailloux Z, Roley SS, Wagner S, Fein D, Pierce K. Early intervention for children with autism spectrum disorder under 3 years 
of age: recommendations for practice and research. Pediatrics. 2015;136(S60-81.

[17] Den Houting J, Adams D, Roberts J, Keen D. Exploring anxiety symptomatology in school-aged autistic children using an autism-specific assessment. Research in Autism Spectrum Disorders. 2018;50:73-82.

[18] Mathyssek CM, Olino TM, Hartman CA, Ormel J, Verhulst FC, Van Oort FV. Does the Revised Child Anxiety and Depression Scale (RCADS) measure anxiety symptoms consistently across adolescence? The TRAILS study. International journal of methods in psychiatric research. 2013;22(1):27-35.

[19] Duvekot J, van der Ende J, Verhulst FC, Greaves-Lord K. Examining bidirectional effects between the autism spectrum disorder (ASD) core symptom domains and anxiety in children with ASD. Journal of Child Psychology and Psychiatry. 2018 Mar;59(3):277-84.

[20] Kushki A, Chau T, Anagnostou E. Handwriting difficulties in children with autism spectrum disorders: A scoping review. J Autism DevDisord. 2011:41(12):1706-16.

[21] Kolpakova LO. Visual support in children with autism spectrum development as a tool for changing problem behavior. 2016;21 (3).

[22] Allen KA, Bredero B, Van Damme T, Ulrich DA,
Simons J. Test of gross motor development-3 (TGMD-3) with the use of visual supports for children with autism spectrum disorder: validity and reliability. J Autism DevDisord. 2017;47(3):813-33.

[23] Alderson-Day B. Verbal problem-solving difficulties in autism spectrum disorders and atypical language development. Autism Research. 2014;7(6):720-30.

[24] Macdonald L, Trembath D, Ashburner J, Costley $D$, Keen D. The use of visual schedules and work systems to increase the on-task behavior of students on the autism spectrum in mainstream classrooms. Journal of Research in Special Educational Needs. 2018;18(4):254-66.

[25] Zwaigenbaum L, Bauman ML, Choueiri R, Kasari C, Carter A, Granpeesheh D, Mailloux Z, Roley SS, Wagner S, Fein D, Pierce K. Early intervention for children with autism spectrum disorder under 3 years of age: recommendations for practice and research. Pediatrics. 2015;136(1):S60-81.

[26] Escobedo, L., Nguyen, D.H., Boyd, L., Hirano, S., Rangel, A., Garcia-Rosas, D., Tentori, M. and Hayes, G., 2012, May. MOSOCO: a mobile assistive tool to support children with autism practicing social skills in real-life situations. In Proceedings of the SIGCHI Conference on Human Factors in Computing Systems (pp. 2589-2598). 